Revista de la red interuniversitaria de estudios sobre las literaturas rioplatenses contemporáneas en Francia

$8 \mid 2013$

Argentina y Uruguay: lecturas del país vecino en la literatura rioplatense contemporánea (siglos XX y XXI)

\title{
Geografías ficcionales : El Uruguay de Copi
}

Ilse Logie

\section{OpenEdition}

\section{Journals}

Edición electrónica

URL: http://journals.openedition.org/lirico/985

DOI: $10.4000 /$ lirico.985

ISSN: 2262-8339

Editor

Réseau interuniversitaire d'étude des littératures contemporaines du Río de la Plata

Referencia electrónica

Ilse Logie, «Geografías ficcionales : El Uruguay de Copi », Cuadernos LIRICO [En línea], 8 I 2013, Puesto en línea el 01 enero 2013, consultado el 30 abril 2019. URL : http://journals.openedition.org/lirico/985 ; DOI : 10.4000/lirico.985

Este documento fue generado automáticamente el 30 abril 2019.

\section{(c) $)(9)$}

Cuadernos LIRICO está distribuido bajo una Licencia Creative Commons Atribución-NoComercialSinDerivar 4.0 Internacional. 


\title{
Geografías ficcionales : El Uruguay de Copi
}

\author{
Ilse Logie
}

\section{El topos del Uruguay en la literatura argentina}

1 Este trabajo se centrará en la construcción de geografías ficcionales y en la posibilidad que los procedimientos puestos en obra, para alcanzar tal efecto, ofrecen a la hora de derivar no tanto un núcleo ideológico, sino sobre todo el proyecto poético de los autores implicados. A este respecto, son particularmente interesantes y significativos los imaginarios que forjan las literaturas nacionales acerca de sus países vecinos. Para el caso de la Argentina, el 'otro' más cercano es, desde luego, la República del Uruguay, y el texto que plasmó la supuesta 'identidad' uruguaya del modo menos convencional y más rupturista es, sin lugar a dudas, la novela breve L'Uruguayen (1972), de Copi. En un primer apartado, situaremos la novelita en una nutrida tradición argentina de representación del Uruguay. En el análisis propiamente dicho del texto, destacaremos de qué estrategias discursivas se valió Copi para llevar a cabo su operación iconoclasta, para luego examinar si es posible trazar líneas de continuidad entre sus exageraciones grotescas en materia de identidad nacional y algunos planteamientos posteriores. Veremos que L'Uruguayen se muestra un precursor de cierto linaje de textos, cuyo mayor representante contemporáneo es uno de los grandes promotores de Copi, César Aira. Pese a ser muy diferente de L'Uruguayen, una novela como Los fantasmas (1990) tiene en común con la nouvelle de Copi el desarrollo de una 'teoría' arbitraria de la identidad nacional de un país vecino, en este caso Chile, revelada como máxima diferencia intelectual y física.

2 Aunque, en sus principios, la literatura uruguaya haya estado estrechamente relacionada con la argentina, y aunque mucha de la literatura argentina haya sido compuesta en el Uruguay y gran parte de la uruguaya publicada en Buenos Aires, este alto grado de interpenetración entre ambos países disminuyó con la consolidación de las dos repúblicas, cuyas fronteras son, como suele ocurrir, en gran medida artificiales. Si las 
fuertes afinidades culturales hacen que siga siendo unánimemente aceptado hablar de una identidad cultural rioplatense, sobre todo en lo que concierne a la Argentina y al Uruguay, la hegemonía argentina y la peculiaridad de las relaciones entre los dos países contribuyeron a la construcción de un mito acerca del vecino oriental, que tiene una larga tradición y que, pese a algunas reconfiguraciones, perdura hasta hoy en día. Para el ciudadano argentino no hay cosa más rara que el Uruguay, ya que es un país yuxtapuesto, que no es del todo un país por su relación de parte a todo con la Argentina. Se trata aquí de un lugar común del imaginario porteño: Uruguay está simultáneamente cerca (del otro lado del río) y lejos (es la Banda Oriental primero, la República Oriental después ; los uruguayos son el Oriente, también en el sentido figurado que Said introdujo en 1978). Esta constelación ha dado lugar a una 'geografía imaginaria', aquello que se construye fundamentalmente a través de la literatura y que puede llegar a sustituir la geografía nacional. Dice César Aira en su análisis de L'Uruguayen: «El Uruguay es una Argentina miniaturizada, es decir, objeto artístico a priori» (1991: 20). El Uruguay resulta «el paisaje obligado del escritor argentino », « lo inverificable » (p.20), la ficción.

En un lúcido ensayo recogido en $E l$ punto vacilante, «La parte por el todo. Alegato oriental », Sergio Chejfec ${ }^{1}$ ha identificado el Uruguay como el lugar metafórico argentino, asociado a ciertos valores como la serenidad y la hospitalidad, el anticonsumismo y el republicanismo. Tan similar y, sin embargo, tan distinto de la otra orilla, el Uruguay es, para la literatura argentina, "una deriva, el sueño preservado de una Argentina imposible» $(2005: 40)$, que permite hablar de lo propio desde la similitud y la extranjería, y realizar un cruce doméstico, de frontera política pero no cultural. Representa, en primer lugar, «la nostalgia de un breve momento de expansión moderna e igualitaria, una arcadia política que reúne las ilusiones de transformación perdidas en el siglo XX, y que se condensa en una figura paisajística, la costa urbanizada de la orilla uruguaya del Río de la Plata » (Silvestri, 2004). Ese fantasma oriental que acompaña al paisaje literario argentino, y que se plasma en motivos como el cruce de orilla, la fascinación ejercida por la inmutable personalidad de Montevideo o la evocación de la bella y seductora costa uruguaya como locus amoenus, se ha formado, según Silvestri, en tres momentos clave : 1) Montevideo como uno de los lugares preferenciales de refugio argentino durante la dictadura de Rosas - recordemos que la primera novela de la literatura argentina, Amalia de Mármol, 1851, comienza contando un intento de travesía hacia el Uruguay ;2) el exilio durante el peronismo y 3 ) el hecho de que la dictadura no lograra destruir esa imagen, por lo que el sueño del Uruguay retorna después de la caída del régimen autoritario. Por diferentes motivos, pasar de la Argentina al Uruguay ha llegado a constituir un viaje arqueológico hacia las décadas doradas del Estado de Bienestar, cuando todavía se conservaban los valores éticos de libertad y distribución equitativa.

Son múltiples y muy variados los ejemplos. Ya Borges, con su característica ironía, consideraba The Purple Land (1885) de W. H. Hudson « la mejor novela argentina »-una novela en la que un autor británico cuenta un viaje en el que se cruza de norte a sur todo el Uruguay-, y alaba el carácter salvaje y auténtico del pequeño país. Por su parte, el relato de Bioy Casares, "De la forma del mundo », de 1976 (publicado en El héroe de las mujeres) explota en el registro fantástico la idea del Uruguay como lugar extraño: el protagonista encuentra un túnel secreto que une los dos países, y que da acceso a una felicidad breve y precaria, que por su índole utópica sólo hubiera podido situarse en territorio uruguayo. 
5 Pero el topos del Uruguay como refugio cercano de una situación que en la Argentina parece difícilmente sostenible, o como escenario sobre el cual se proyectan ideas, sueños e imágenes se prolonga hasta hoy en día ${ }^{2}$. Algunas de las novelas más emblemáticas de la década de los noventa lo contienen y elaboran : $E l$ aire (1992) del propio Sergio Chejfec, $E l$ dock (1993) de Matilde Sánchez o Plata quemada (1997) de Ricardo Piglia. En los tres textos, el Río de la Plata asume un rol protagónico para pensar un lugar dinámico, promotor de experiencias muchas veces contrapuestas. Supone la posibilidad de situarse desde un alter ego en otra realidad. El dock ilustra muy bien esta arraigada connotación utópica. En la historia de Sánchez, una militante es asesinada por las fuerzas militares en un intento de tomar el cuartel de La Tablada. A partir de ese momento, su hijo es cuidado por una amiga de esta activista y ambos viajan clandestinamente al balneario uruguayo de Solís para aislarse, deshacerse de la presión y construir lazos afectivos.

6 Sin embargo, un texto muy sui géneris de la década de los setenta, L'Uruguayen de Copi, se aparta radicalmente de esta tradición de evocar al Uruguay como espacio utópico con fuerte potencial alegórico para inscribirse en otra línea poética, compatible con la estética vanguardista de transgresión del autor. Bajo su pluma, el Uruguay se construye como un artefacto, un objeto artístico que ha roto sus amarras con el referente extratextual y que al lector le parece absurdo. Este relato, inspirado en parte por los años que Copi pasó en el Uruguay, representa el grado extremo de una operación literaria de (auto)exotismo, que volveremos a encontrar en determinado linaje de textos de los años 80. Para comprender mejor su alcance, cabe remitir a la hipótesis formulada por Graciela Montaldo, según la cual autores como Copi (en L'Internationale Argentine), Laiseca (La hija de Kheops) o Aira (Una novela china) sustituyeron el exilio por el exotismo a través de la recuperación del género de aventuras (1993 : 260 y ss). Vista así, a la doble pertenencia nacional de Copi ya sería menos aplicable una interpretación en términos de "extraterritorialidad», tal como esta categoría fue definida por George Steiner, el primero en señalar la importancia que cobró el fenómeno de los escritores plurilingües en la literatura del siglo XX (Beckett, Kafka, Nabokov) y del exilio como su principal impulso. Sostiene Montaldo que lo exótico, a fuerza de exacerbarse tanto en los ejemplos que analiza, se convierte en la ficción misma porque lo que se define como exótico no es otra cosa que lo propio (p.263). De este modo, el exotismo deja de plantearse en primer lugar como un problema de representación para constituirse en garantía de ficción (p.263). Realizando un movimiento que va desde una poética del exilio hacia el autoexotismo, que busca lo lejano en lo familiar, cierta literatura argentina recupera parte de su potencial de fabulación. La insistencia en lo nacional funciona de ahora en adelante como un dispositivo artístico, como apócrifa tradición literaria.

7 La hipótesis de Montaldo ayuda a construir una lectura más satisfactoria de L'Uruguayen, donde la mirada oscila entre exotismo (el del país extranjero) y autoexotismo (el Uruguay como cultura espejo de la Argentina). El mérito no es escaso, teniendo en cuenta que, como muchos de los textos de Copi, esta novelita plantea un serio problema de interpretación, ya que es imposible leerla según los códigos de la verosimilitud, al tiempo que se muestra reacia al desciframiento alegórico o a la recuperación como caso paradigmático de escritura homosexual (lo que hasta cierto punto sí es posible para otras obras del autor). Como veremos a continuación, la obsesión rioplatense de Copi es en parte atribuible a una voluntad posmoderna de deconstrucción de convenciones identitarias, pero sería igualmente reductor pretender que se agota en ella. Interpretar este particular manejo de lo nacional como dispositivo de autoexotismo y, por ende, 
garante de la ficción no resuelve, sin embargo, todas las aporías de la escritura de Copi. Esta expresa una sospecha tan radical acerca de las convenciones que presiden la narración y acerca de la pretensión de representar el mundo que no parece exagerado postular su ilegibilidad deliberada.

\section{Copi frente a los estereotipos nacionales}

8 Raúl Damonte, alias Copi, nació en Buenos Aires en 1939. En 1945, la llegada de Perón al poder condujo a la familia Damonte al exilio, primero en Montevideo, luego en París, donde Copi fue escolarizado y donde aprendió francés, lengua en la que escribiría la casi totalidad de su obra. El padre de Copi fue cónsul del Uruguay en Irlanda. En 1955 la familia, económicamente arruinada, volvió a la Argentina, en donde le tocó vivir a Copi una situación caótica de peronismo, antiperonismo, exilio, retorno, oposición a la Revolución Libertadora, violencia, inestabilidad... que fueron importantes temas de la obra que el autor desarrolló posteriormente en Europa.

En París, donde terminó instalándose definitivamente a partir de 1962, Copi trabajó como dibujante para varias revistas, entre otras para Le Nouvel Observateur, en el que publicó su tira semanal La mujer sentada hasta principios de los años 70. Junto con Fernando Arrabal, Alejandro Jodorowsky y Roland Topor, fundó el grupo de acciones teatrales Pánico. Paralelamente, destacó como actor travesti, escribió piezas de teatro y narrativa (tanto novelas como relatos). Murió de sida en 1987.

Las delirantes historias de Copi abundan en acontecimientos fulminantes y repentinos, cuya violencia posee un carácter gratuito. Se suelen organizar alrededor de la catástrofe y están marcadas por el mal gusto típico de la estética camp (Amícola, 2000), por el absurdo y el exceso. El interés por los seres más alternativos de la sociedad burguesa y por lazos familiares caracterizados por lo criminal y lo monstruoso son tópicos que atraviesan toda la obra del autor, cuya poética ha sido definida como estética "trans» (Link, 2003) por practicar el paso de un sexo a otro, el cambio de una lengua a otra y las múltiples relaciones entre los distintos géneros que conforman otro elemento de transgresión. Su obra toma como punto de partida los residuos de estereotipos ideológico-culturales ${ }^{3}$ y los somete a un desmantelamiento radical, optando por el simulacro como estrategia básica de la representación de la realidad. Al exagerar tanto los tópicos a través de procedimientos como la yuxtaposición y la proliferación o saturación de datos siempre confusos, desestabiliza las certezas identitarias y las exhibe como signos arbitrarios, trátese de las identidades lingüísticas, nacionales, políticas o sexuales y hasta la pertenencia a una especie (muchos personajes se transforman en animales). Como en este artículo investigamos en primer lugar las geografías ficcionales, cabe subrayar el rechazo de toda lógica del territorio presente en la obra de Copi, su empeño en desmantelar al Estado-Nación, toda idea de comunidad nacional o de apropiación lingüística como pactos convencionales de la pertenencia cultural, aunque semejante actitud no está completamente exenta de contradicciones. Es innegable que, acumulados y exhibidos, los estereotipos de los que Copi echa mano y que actúan como memoria de una colectividad, muestran su agotamiento y resultan subvertidos. Aparecen como lo que siempre han sido, según los enfoques de teóricos como Anderson, Gellner, Hobsbawm y otros, que definen los nacionalismos como « constructos » inacabados y relacionales en los que se combinan referentes muy variados, como relatos, guiding fictions o ficciones orientadoras en la terminología de Nicolás Shumway : « Las ficciones orientadoras de las naciones no pueden 
ser probadas, y en realidad suelen ser creaciones tan artificiales como ficciones literarias. Pero son necesarias para darles a los individuos un sentimiento de nación, comunidad, identidad colectiva y un destino común nacional» (Shumway, 2002 : 14-15). Un mito nacional será entonces un cuento contingente que debe ser permanentemente reinventado para que el ciudadano lo reconozca como inalienablemente suyo.

El ejemplo más espectacular de manipulación y deconstrucción de una ficción orientadora en la producción de Copi se encuentra en su pieza de teatro Eva Perón. La pieza fue estrenada en París en 1970, en una pequeña sala de teatro experimental, y la acompañaron el éxito y el escándalo : el teatro quedó dañado a raíz de un atentado que se produjo durante una de las representaciones y al propio Copi se le prohibió el ingreso a la Argentina hasta 1984. Hay que decir que la obra acumula las osadías : no sólo ha hecho del mito de Evita centro de una obra del teatro del absurdo, para colmo escrita en francés, sino que se añade en la representación una profanación para la cual no había indicios en el texto : la 'Primera Dama' del país fue representada por un travesti. De esta manera se pone en marcha un vertiginoso sistema de muñecas rusas: un actor travesti que interpreta a una actriz (Eva Perón) que interpreta el papel de una hegemonía política, el peronismo. Pero Copi no se detiene ahí. Su Eva también resulta sacrílega frente a la idealización forjada por el pueblo, porque descubrimos que su cáncer no ha sido más que una patraña, una puesta en escena, una mentira necesaria para alcanzar la inmortalidad y para mantener a Perón en el poder : para el partido resulta más 'útil' muerta que viva. No muere Eva, sino que ella decide vestir con su traje de gala a su enfermera, regalarle algunas joyas, en resumen, disfrazarla de Evita para apuñalarla en complicidad con el personaje ficticio y transexual de Ibiza, de manera que el cuerpo de la enfermera será la víctima propiciatoria entregada a la adoración pública. El dato histórico que dará lugar al mito de la necrofilia es planteado aquí como una farsa, y el pueblo velará a una enfermera, a una Evita falsa. Eva es retratada como cómplice en la construcción de su propio mito y como asesina a sangre fría. O sea que Copi arruina toda la imagen pública que Eva se construyó, presentando la política como una incesante teatralización cuya condición artificial y fraudulenta Copi revela.

La constitución de lo estereotípico desempeña un papel igualmente importante en el texto narrativo L'Internationale Argentine (1988, de publicación póstuma), cuyo título ya presupone una imposible dialéctica de lo universal y lo particular. Blanco de las burlas es esta vez el 'argentino de París', al que encarna el alter ego caricaturizado del autor, el poeta grandilocuente Darío Copi, como si, al desplazarse, la prepotencia, el machismo, la homofobia, la eurofilia... se manifestaran elevados a la segunda potencia. París simboliza aquí el lugar de la libertad extrema donde todo es posible, incluida la organización de un movimiento de emigrados argentinos que se propone llegar a la presidencia de su nación para cambiar la sociedad gracias a dos elementos característicos : su radical apoliticismo y su imaginación. Urde la conspiración llamada 'Internacional Argentina' Nicanor Sigampa, un negro colosal y millonario que ha sido estrella nacional de polo y que, por muy negro que sea, es producto típico de San Isidro y educado en Oxford. Huelga decir que, al lanzar la estrafalaria idea de fundar una plataforma política en un proyecto literario, Copi denuncia la política argentina como una sucesión carnavalesca de intrigas en las que intervienen prejuicios raciales y religiosos.

13 Como hemos visto, la obra de Copi causa perplejidad en su lector, y no se deja asimilar fácilmente a paradigmas interpretativos existentes, como la extraterritorialidad. Si bien es verdad que el autor imagina el Río de la Plata desde una mirada exterior, instalándose 
en la propia lengua como un extranjero, también lo es que no considera su condición de exiliado como algo doloroso, sino que parece tomarla como una posición favorable que posibilita una descodificación no limitada por un sentimiento de identidad cerrado (en L'Internationale Argentine, por ejemplo, se burla del exilio ; con Eva Perón, al estar radicado en Francia evita problemas de recepción en Argentina). Más pertinente parece ser, por lo tanto, plantear la paradoja siguiente : ¿a qué sistema literario pertenece el apátrida Copi ? ¿Cómo explicar que su obra significa lo argentino sin que persista en ella un deseo de alcanzar respuestas clave que permitan ver a la Argentina como un conjunto que tenga sentido ? A nuestro modo de ver, la auténtica originalidad y la fuerza demoledora de Copi estriban precisamente en su aproximación sesgada a la argentinidad. Pero la escisión que recorre la obra de Copi es más compleja : no es meramente la que opone la Argentina a Francia, sino que su universo surge del choque de tres culturas diferentes. En varios de sus textos, como es el caso en L'Uruguayen, pero también en su pieza Cachafaz (1993), que transcurre en un conventillo montevideano, llama la atención el desvío por el Uruguay, donde el escritor pasó varios años de su infancia y que aparece explícitamente representado como un tercer espacio intermedio. Es sumamente llamativo que Copi se coloque en este lugar "oriental», "otro", para escribir sobre lo argentino, un lugar evocado como la otra dimensión del ámbito rioplatense, como si deseara multiplicar las instancias mediadoras e intensificar así, a través de esta triple mirada, el extrañamiento.

\section{Comment peut-on être uruguayen $?^{4}$}

El primer experimento narrativo de Copi, L'Uruguayen (1972) ${ }^{5}$, narra las peripecias de un desconcertado viajero francés de paso por Uruguay. No se explica al lector cómo ni por qué el protagonista ha ido allí, simplemente está en Montevideo, en tierras extrañas. La novela se presenta bajo forma de carta, una carta que se compone de un párrafo único sin subdivisión ni interrupción, y que el narrador dirige a su maestro francés, al que simultáneamente insulta porque representa una tradición cultural que « asquea » (p.90) : la de la erudición y del saber asimilado. En su informe, el narrador, que hace vida de turista con su perro Lambetta, se ocupa de describir las cosas asombrosas que pasan en Montevideo y las costumbres de los uruguayos - respecto de su modo de vivir, su idioma (un lenguaje completamente estrafalario e imaginario) y su conceptualización del mundo, actitud que recuerda la famosa exclamación de Montesquieu en sus Cartas persas: "Comment peut-on être persan?». ${ }^{6}$

15 Al principio, el narrador parece embarcado en una misión antropológica. Proyecta sobre el uruguayo una mirada etnográfica: da explicaciones etimológicas seudocultas, pone notas apócrifas a pie de página, como en los tradicionales tratados del género. A primera vista, surge la impresión de que Copi postula así una verosimilitud propia de la tradición literaria del relato de viaje. Esta tradición, marcada por el eurocentrismo (al que Pratt dedicó un estudio imprescindible) y que conoció su auge a partir del siglo XVIII, está convocada desde el paratexto del título y condiciona las expectativas del lector. Estas expectativas son sin embargo defraudadas, ya que el relato no nos enseña nada sobre el Uruguay y, al contrario, satiriza el discurso antropológico. Sabemos que construir una identidad es a la vez 'diferenciarse' y 'parecerse', y también que toda identidad depende de la alteridad, que todo 'nosotros' se determina antes que nada por el modo de concebir a sus 'otros' y de relacionarse con ellos. La estrategia que pone en obra Copi en L'Uruguayen es la de estirar al máximo la alteridad porque representa al uruguayo (cuya 
cultura, para alguien venido de fuera, resulta casi intercambiable con la argentina) como al otro absoluto, como diferencia desmesurada comparada con el país vecino. Aparecen condensados en L'Uruguayen todos los prejuicios y malentendidos mutuos. Esta mirada desrealizadora sobre el Uruguay se justifica, ya que Uruguay, como hemos visto en la introducción, representa el exotismo para un argentino. Tampoco podían faltar las rivalidades entre argentinos y uruguayos, que aparecen tematizadas cuando un grupo de ricos turistas argentinos, prepotentes y arrogantes como yankees, invaden la capital uruguaya en un yate (p.106). El Uruguay inevitablemente se manifiesta entonces como escenario veraniego, como la Argentina que se va de vacaciones a Punta del Este o a Colonia. Para colmo, los sucesos uruguayos son retransmitidos por la televisión argentina y representados desde ese punto de vista.

Las relaciones humanas en L'Uruguayen no son en absoluto pacíficas. La visión del narrador es cáustica, provocativa y hasta macabra. Los personajes cometen crímenes horrendos, se entregan a la sodomía forzada (el presidente uruguayo se hace sodomizar por el "papa argentino", un peligroso traficante de blancas que está de visita en Montevideo), la antropofagia y la necrofilia (confesión del narrador : « He hecho el amor a la señora negra [muerta] sobre el mostrador del estanco»(p.114)) según unas ritualidades exacerbadas. La trama, imposible de resumir, culmina en una escena matrimonial entre el narrador y el presidente del Uruguay, que ha conseguido escaparse de la lascivia del papa argentino. Tal agresividad destruye otro aspecto del mito de lo uruguayo : la idea del pequeño país donde no ocurre nunca nada, la «Suiza de América » donde todo es estable, corriente y risueño. El Uruguay de Copi toma, al contrario, un cariz apocalíptico : es escenario de una serie de cataclismos « típicamente uruguayos » (p.135): el viento sopla fuerte, las dunas cambian de lugar, las fronteras resultan movedizas, el narrador encuentra a su perro sepultado bajo la arena al poco tiempo de haber llegado a la ciudad. Muy pronto, lo real empieza a modificarse y ya nada sigue siendo lo que parecía ser. Se viene abajo la pretensión antropológica del narrador porque, nada más llegar, ya pierde sus escasos puntos de referencia. Por las catástrofes que sobrevienen, la arena cubre Montevideo y hasta llega a desaparecer la capital, inundada por el mar que ha avanzado. Desaparecen los habitantes y el viajero se queda solo, como único superviviente. El Uruguay ha cambiado tanto que lo que hasta ahora se nos ha contado ya ha quedado caduco ; Montevideo se ha vuelto una ciudad fantasma, surreal. Se suceden los golpes de teatro: después del apocalipsis, los habitantes se ponen a resucitar, pero más tarde el país entero se reduce de tamaño, el mar se esfuma y el narrador ya no puede salir del país. La casa presidencial empieza a brincar y el viajero se muda, con el presidente, a una gruta en la playa. No se puede ir más allá : al final todo está trastocado y es imposible ofrecer una interpretación en clave mínimamente realista o según pautas verosímiles. Al realizar de una forma tan radical el imaginario, Copi lo agota y lo pone en crisis.

\section{Situación enunciativa}

El dispositivo narrativo del texto, sumamente complejo como lo ha demostrado Patricio Pron en su pormenorizado análisis narratológico (2006), ofrece algunos indicios que permiten superar una lectura en clave (auto)exótica. De lo que se trata es de desplazar la interpretación de L'Uruguayen hacia otro nivel de análisis, para poder leerlo con más provecho como una libre representación del Río de la Plata, basada en ciertas 
conceptualizaciones metaficcionales, y no como el producto de un ejercicio consciente de la memoria familiar o de la historia. Uruguay sólo parece existir como creación verbal. El aparato paratextual ya es significativo al respecto. Aunque escrita en la lengua adquirida de Copi y no en la materna, la novelita va precedida de una advertencia al lector en cuanto a la variante del francés que se le ofrecerá, una variante no normativa :

A l'Uruguay, país donde pasé los años capitales de mi vida, el humilde homenaje de este libro, escrito en francés, pero pensado en uruguayo (p.85).

O sea que, de entrada, Copi reivindica el cambio de lengua como un recurso para distanciarse de situaciones en las que estaba comprometido, como estrategia deliberada de exorcismo. A esa distorsión lingüística se añade el título de la novelita, que debe leerse como una forma de proclamar el locus de enunciación del narrador, que además se llama Copi, como es casi siempre el caso en las ficciones del autor. No hay que olvidarse que el viajero se identifica con ese bicho raro y que ya desde el título él ES el uruguayo, y en un momento dado, lo encarna por antonomasia al tomar las riendas del país, como si 'Uruguay' fuera una categoría completamente relativa, un gentilicio vaciado enteramente de su sentido convencional, como si hubiera sufrido un desplazamiento no sólo de las coordenadas espaciotemporales, sino también identitarias, ya que se puede ser argentino y uruguayo al mismo tiempo (como, en otro orden de cosas, se puede ser hombre y mujer al mismo tiempo: figura plasmada en la omnipresencia del travesti). La identidad nacional aparece aquí, pues, no como esencial, sino como situacional y, además, ligada a la enunciación : estoy en Uruguay, ergo soy uruguayo ${ }^{7}$. Esta identidad situacional está tematizada, pero también puesta en discurso, porque es ahí donde se pueden verificar pasajes significativos (soy uruguayo porque estoy en Uruguay y mi situación enunciativa determina mi identidad).

Hay que subrayar, asimismo, que el texto tiene un estatuto ontológico francamente oximorónico porque la carta no puede llegar, quedará de hecho sin destinatario al convertirse el narrador en el único superviviente del Uruguay (p.114). Y si alguna vez llegara, no quedaría de ella ni rastro, puesto que el viajero, en un gesto paradójico y vanguardista de borrón y cuenta nueva, pide a su interlocutor una colaboración destructiva, un acto de anulación: le pide que borre lo que vaya leyendo (p.89). L'Uruguayen postula, en otras palabras, un lector modelo que violente lo escrito a través de la tachadura, proponiendo así su propia disolución. Hay que vincular esa lectura no realizada con el rechazo de la memoria, otro eje central de la producción de Copi. Si de lo que se trata es de levantar un contrarrelato de la identidad monolítica y unitaria del sujeto, una consecuencia lógica consiste en no aceptar las imposiciones de una memoria que establezcan límites a la proliferación del imaginario y enfocar el olvido como fuente de liberación. De allí el alto grado de inestabilidad de la trama, que se reduplica en la construcción de personajes que transmiten sucesos que no recuerdan y en una enunciación que convierte el relato en inasible. Por cierto, la relación conflictiva entre memoria y escritura se manifiesta en cada texto de Copi de manera ligeramente diferente. Así, en Le bal des folles (El baile de las locas) es el narrador quien sufre amnesia : comienza una y otra vez una novela, la que estamos leyendo - y una y otra vez la olvida. En Virginia Woolf a encore frappé (Virginia Woolf ataca de nuevo) también se tematiza la falta de ideas para completar el libro homónimo. Y en La cité des rats ( La ciudad de las ratas), 'Copi' ni siquiera se presenta como escritor, sino como mero traductor. Esta novela, que no fue traducida hasta hace muy poco al español, constituye en varios aspectos una interesante prolongación de L'Uruguayen. Al igual que ésta, se presenta como una novela epistolar de 
aventuras que recoge las cartas que una rata (animal emblemático para Copi, que simboliza al 'otro radical') escribe a su maestro (que aquí toma el nombre de Copi) acerca de su vida en las alcantarillas de París y su extravagante viaje por el Nuevo Mundo. Volvemos a encontrar también la faceta seudoetnológica, ya que en la perspectiva de esa rata de París, la Argentina, reducida a sus cataratas del Iguazú, no es más que un intervalo geográfico entre las otras dos maravillas naturales del subcontinente: el estrecho de Magallanes y el delta del Amazonas.

Se observa, entonces, que el delirio autodestructivo no sólo gobierna L'Uruguayen en cuanto a su trama, en la que se suceden eventos catastróficos que producen aniquilaciones masivas y amenazan con hacer desaparecer hasta la lengua, que termina por reducirse a la palabra «rata » (p.125), la palabra más representativa de la obra de Copi. En el plano discursivo, la autoanulación de la lectura, si bien afecta en primera instancia al lector intradiegético (el antiguo maestro), plantea, asimismo, una paradoja de recepción en el nivel extradiegético, ya que es legítimo preguntarse para quién escribía Copi, para qué comunidad de lectores. ¿No tiene esa comunidad un perfil híbrido, al componerse de seres dotados de horizontes de expectativas divergentes y hasta incompatibles? L'Uruguayen se dirige tanto a un público francés como a un público rioplatense, el único capaz de leer este conjunto de tópicos que constituyen la escena de Copi. La literatura de Copi es tan anómala dentro de la cultura argentina como dentro de la francesa : aunque el escritor construyó su identidad por referencia al campo parisino, su estilo es percibido por la crítica francesa como extranjero, minimalista y excesivo a un tiempo. Copi tampoco comparte con sus predecesores franceses del teatro del absurdo su predilección por los espacios abstractos, siendo los suyos reducidos pero siempre identificables. ¿Por qué, entonces, esta insistencia en las formas nacionales que, por otra parte, el autor rechaza? ¿Qué lector francófono comparte esa compulsión estereotípica que permite modelizar 'la argentinidad', puede captar la ironía subyacente en ese conjunto de clichés o descodifica la cadena intertextual presente en filigrana en cada texto de Copi? Si, como se sabe, el estereotipo es tanto efecto de escritura como de lectura, el lector ideal de Copi es el lector que lo lee en traducción, el que lo lee oblicuamente, por persona interpuesta - a través de sus herederos argentinos como Aira, Laiseca o Cucurto (véase Pron, 2007, para una discusión de la influencia de la singular poética de Copi en la literatura argentina) - o, sencillamente, el que no lo lee. El pacto de lectura que propone L'Uruguayen parece ser un comentario a esta última aporía del destinatario 'inexistente'. Y la profecía se ha cumplido : efectivamente, la recepción de Copi ha sido problemática, y en la Argentina tardía. Su reconocimiento ha sido primero internacional, y sólo después rioplatense. En los últimos años y sobre todo desde la publicación del Copi de Aira (1991), se ha producido una operación de rescate de la figura de Copi en la propia Argentina, con estudios importantes como los de Rosenzvaig (2003), Amícola (2000), Pron $(2006,2007)$ o Link (2003). Temas como su extraterritorialidad (Weiss, 2003), su estética del travestismo (Amícola, Link) o la continuidad y el vaivén constante entre distintas facetas de su obra, más en particular la importancia fundamental de su obra gráfica allí donde anteriormente los estudios se centraban en su actividad como dramaturgo y escritor (Vázquez, 2009) son algunos de los ejes más productivos en esta relectura de Copi. Recientemente, han sido publicadas nuevas ediciones de su obra en la Argentina (por la editorial El Cuenco de Plata) y en España (las Obras en dos tomos en la colección Otra vuelta de tuerca, de Anagrama), y ha tenido lugar en Buenos Aires el estreno de L'Uruguayen, llevado a las tablas por el artista visual francoargentino Roberto Plate, a quien la nouvelle iba dedicada desde la primera edición. 


\section{Ceci n'est pas une pipe}

21 A fin de cuentas, el narrador de L'Uruguayen resulta todo menos fidedigno, por lo que el lector no aprende nada sobre 'el uruguayo', por mucho que el título hubiera prometido revelar alguna información instructiva al respecto. En las páginas 104-105 aparece un episodio que ilustra el principal propósito del texto, una auténtica mise en abyme, un metacomentario que avisa que el universo de la novelita no es referencial sino que parodia rotundamente el principio de verosimilitud, y que le impide al lector interpretar el texto al modo realista, psicologizante o alegórico. Cuando la catástrofe ha eclipsado la ciudad de Montevideo, el narrador dibuja sus contornos en la arena con un trozo de madera (p.104) y en una pizarra (p.121). Dibuja el lugar de las aceras, de las calles, de las casas, los coches y circula únicamente por esas calles y aceras. Los barrios de la capital son etiquetas que pueden llevarse bajo el brazo. Como la realidad ha sido anulada y se ha vuelto inaccesible, el narrador se refugia en una creación propia, una maqueta que hace las veces de la ciudad de antes. Conversa con los uruguayos dibujados que hasta llegan a sonreírle. Más adelante, se multiplican las alusiones a los poderes de demiurgo que posee el protagonista-viajero, que cual brujo, mueve las cosas a su antojo, obrando milagros y mutaciones : "Navidad llegará cuando yo lo decida » (p.115) o "Anteayer pensé en una vaca con tal fuerza que acabé viendo la palabra vaca escrita en grandes letras de neón en la pared de enfrente de mi hotel » (p.116). La desaparición y la resurrección de la ciudad y de los habitantes parecen ser fruto de decisiones del narrador cuyo 'Uruguay' se sale de la geografía y sólo funciona en la ficción. Cuando los dibujos resultan parcialmente borrados, al narrador le da pereza volver a hacerlos y salta a un mayor nivel de abstracción: los sustituye poniendo rótulos, escribiendo el nombre de cada objeto o persona con grandes caracteres sobre ellos - por ejemplo escribe «coche » sobre los coches o « Mimi » sobre el sombrero de la señora que le había sonreído (p.105); al dibujo de una casa agrega « las acacias »; al de un árbol, « roble », etcétera. Cuando el papa le da la bendición al narrador (p.132), éste escribe la palabra «bendición» en un trozo de mantel y se lo entrega, o sea que lo que circula en el intercambio humano no son los objetos en sí, sino sus denominaciones.

La insistencia en el dibujo y en la maqueta permite considerar L'Uruguayen como un condensado de la trayectoria artística de Copi, ya que invita a leer la obra en la intersección del comic, la ficción narrativa y el teatro. Rosenzvaig (2003) ha llamado la atención sobre la importancia de los 'umbrales' que en la producción de Copi se cruzan constantemente, como si de vasos comunicantes se tratara: un ejemplo de 'umbral' son los cambios permanentes y rápidos de un medio al otro (del comic al teatro, a la novela). Según Laura Vázquez (2009), que ha estudiado la obra gráfica de Copi, sus comics son « anticinematográficos» en el sentido de que rompen con la construcción espacial y temporal que caracterizaba a las viñetas al uso, por lo que van « a contracorriente de la historieta hegemónica » e introducen una renovación estilística. En ellos no hallamos una sucesión de dibujos para desplegar una historia, sino que el tiempo está concentrado en cada viñeta. $Y$ en cada escena, cada recorte temporal, suceden las situaciones marginales y excéntricas de sus relatos, una técnica que se puede comparar con la que el autor utiliza en su obra narrativa. Llegadas a su auge en el período bisagra de los años 60, las tiras de Copi dan cuenta de cierto espíritu de época y se inscriben en la emergencia de un discurso modernizador sobre la cultura de masas, fomentado por revistas argentinas como Tía 
Vicenta y 4 Patas, o por instituciones como el Di Tella de Buenos Aires. Pero sólo es síntoma de época hasta cierto punto ; por su postura extremadamente disruptiva, la obra historietística también se perfila como singular y excepcional. La idea de los vasos comunicantes entre modalidades del arte se aplica asimismo al teatro. Como ya queda dicho, a partir de su residencia permanente en Francia, además de consolidarse como dibujante, Copi se integró en las experiencias estéticas del grupo Pánico, un colectivo cuyo programa de acciones teatrales y experimentación artística tenía una fuerte lógica autodestructiva. Según Link (2003 : 106), las puestas en escena del grupo rompieron con toda idea de montaje tradicional. L'Uruguayen tiene la dinámica imparable de las piezas del grupo Pánico y de las del propio Copi : está lleno de golpes de teatro ; cualquier lugar, pero particularmente Montevideo, se convierte en un decorado teatral y el narrador tematiza explícitamente la duplicidad de la representación («No les falta una cierta elegancia en alguna de sus costumbres. Por ejemplo la ceremonia en la que exorcizan sus dobles », p. 97) o interpreta él mismo varios papeles.

Uno de los cuadros más célebres del surrealista belga René Margritte es Ceci n'est pas une pipe, esto no es una pipa, realizado a finales de los años 20 del siglo XX, en el que plantea el problema de las relaciones entre un objeto pintado y el real. Retrata meticulosamente una pipa, y debajo, con igual precisión, pone la leyenda "Ceci n'est pas une pipe ", cuestionando la realidad pictórica. Sostiene así que tanto la representación plástica/ icónica como la lingüística son básicamente autorreflexivas. El dibujo en L'Uruguayen remite a este cuadro; sólo que Copi parece volver a adoptar la actitud ingenua, parece restablecerla al decir " esto ES una pipa », haciendo abstracción de la lección de Magritte, después de haberla asimilado y dado por descontada. Es más : sobre ella edifica su pacto de lectura : estamos dentro del reino de la ficción, y aquí valen exclusivamente sus reglas. Esta puesta en abismo ofrece su clave de desciframiento, se dirige a un lector intradiegético (el maestro pedante que cree ingenuamente en la identificación esquemática entre mundo y literatura, en la transparencia de las consignas escolares) y simultáneamente al lector extradiegético, que sí debería entender que el texto que lee es una construcción inestable, levantada en « la arena » a fuerza de imaginación y palabras. Copi supera la arbitrariedad y la intercambiabilidad de los signos, creando un Uruguay delirante. Ha abandonado toda idea de un original, de un universo referencial que debiera ser representado o explicado; la mímesis ha llegado aquí a su grado cero, al valor puro del arte en su proceso de creación. Si la pipa de Magritte, que todo el mundo juraría que ve, no es una pipa, más vale renunciar a toda ilusión representacional. El Uruguay de Copi no pretende ser más que un dibujo esbozado en la arena que se autodestruye, un cuento fabulado en plena libertad.

\section{Los chilenos son así : seudoestereotipos en Los fantasmas de César Aira}

Ya en los 70, Copi apostaba por una autonomía artística de una radicalidad vanguardista, preparando de este modo la línea de la invención absoluta o vuelta al relato, inaugurada en los 90, al interior del sistema literario argentino por escritores antirrepresentativos como César Aira. Junto con Gombrowicz, Copi pertenece a la categoría de autor que opera como modelo en Aira. Este último contribuyó activamente a establecer su propia genealogía literaria y reclamó a Copi como 'precursor' en el sentido borgiano cuando le dedicó, en junio de 1988, una serie de conferencias que más tarde se publicaron bajo 
forma de libro. De este modo, sacó de la marginalidad esa estética de la inverosimilitud extrema, dirigida a interpelar ciertas construcciones de la realidad y de la política, y característica de lo que se gestó entre finales de la década de los 60 y mediados de los 70 en la Argentina, pero abortada por los avatares históricos posteriores y por el quiebre autoritario. Las afinidades son llamativas : una narrativa propulsada por la continuidad como procedimiento o la « huida hacia delante ", la extrañeza como efecto de lectura que define los textos de ambos, la importancia del lector que forma parte del mecanismo de construcción de las historias, por no ir más lejos (Montaldo, 2005 ; Contreras, 2002). Sin embargo, si en la obra de Aira se han resucitado en cierta medida los planteamientos ficcionales tomados de la vanguardia, ha sido bajo forma de un reciclaje que los pasa por el filtro de la massmediación, el kitsch audiovisual y la trivialidad (Montoya Juárez, 2010). La recuperación del surrealismo y el dadaísmo, de la literatura como ready-made duchampiano tiene mucho en Aira «de estrategia posmoderna, una vuelta a la vanguardia, como el crítico y el propio autor reconocen, pero consciente de su imposibilidad y a partir del reciclaje de materiales procedentes de un contexto cultural catalogable como posmoderno » (Montoya Juárez, 2010 : 139).

Una novelita que juega con las ficciones identitarias y, en este sentido, comparable con L'Uruguayen es Los fantasmas (1990), punto de partida del ciclo novelesco urbano de Aira. Hace falta formular aquí una observación preliminar, y es que, contrariamente a la omnipresencia del imaginario uruguayo en la literatura argentina, llama la atención la exclusión textual o literaria de Chile en la tradición argentina, por mucho que Sarmiento escribiera su Facundo, texto fundacional por antonomasia, exiliado en Chile. Aira intenta 'resolver' el problema de 'lo chileno' escribiendo Los fantasmas, el relato de una familia chilena itinerante cuyos integrantes viven como cuidadores en un lujoso edificio en construcción situado en Buenos Aires. Además de los vigilantes chilenos y los otros obreros que pasan allí sus días, el edificio es frecuentado por fantasmas lascivos e indolentes, todos machos y desnudos, que algunos personajes tienen la capacidad de ver y otros no. En este sentido, Los fantasmas es una novela que infringe las convenciones de la verosimilitud desde la aparición de esos seres extraños que «subían y bajaban flotando, inclusive a través de las losas» (p.9) y que proyectan su mirada lúdica sobre el espacio. Personaje central del relato es Patricia, la Patri, de 14 años, hija de la pareja de serenos chilenos, que traba relaciones con los fantasmas y desarrolla una pasión por ellos que coincide con su despertar sexual. Durante la cena de fin de año en su familia, los fantasmas invitan a la Patri a su propia fiesta. Ella acepta y vive una mutación, que desemboca en su muerte. Aira, evidentemente, no la retrata como si fuera un personaje realista : aparte de dotarla de cierto poder sobrenatural, pone en su boca divagaciones etnológicas, que no se corresponden con su edad, sobre los aborígenes australianos y la geometría de los polinesios.

El núcleo de la novelita reside en las reflexiones metatextuales, que giran en torno a lo construido y lo no construido en las artes, y a la superioridad de la literatura. Otro eje del discurso conceptual es la comparación sistemática entre la idiosincrasia de los argentinos y los chilenos, en la que resuenan los estereotipos nacionales. Algunos de estos estereotipos son más o menos banales y hasta plausibles ( Los chilenos eran diferentes, más pequeños, más serios, más compuestos. Y algo más que eso: [...] respetuosos, laboriosos, muy especiales trabajando ", p. 18), otros no hacen más que resaltar la ironía absurda de todo lugar común porque generalizan presentando como leyes causales o verdades absolutas características específicas, anecdóticas y hasta contradictorias ( «os 
chilenos, todos los hombres chilenos, hablan bajito y con un acentito de mujer ", p. 116; «[Elisa] [e]ra bastante casera, como todos los chilenos, cuando no son viajeros por excelencia », p. 45). Hacia el final de la novela, los mismos personajes ponen en duda la validez de los rasgos identitarios que han venido proponiendo. Al fabricar seudoestereotipos, Aira se burla de la actitud acomodaticia del hombre, que se conforma con la repetición de burdas inexactitudes y con la mecánica de los lugares comunes. $\mathrm{Al}$ igual que L'Uruguayen no nos instruye sobre el Uruguay, no aprendemos nada sobre los chilenos en Los fantasmas. La 'chilenidad' resulta ser una categoría gratuita y vacía, que se sostiene en peticiones de principio falaces, como cuando el narrador nos presenta a Roberto : «Parecía argentino, cosa que se explicaba porque lo era parcialmente; aunque, desde ya, era inmensamente más chileno que argentino» (p.99). Aira nos ofrece una cartografía enteramente ficcional y resueltamente antimimética, que deja ver cuán rígidas tienden a ser las redes de pensamiento con las que abordamos la realidad. La operación es similar en muchos aspectos : presentación de lo que es muy cercano como algo radicalmente otro, al tiempo que se mina desde dentro la validez de las observaciones sobre los rasgos identitarios chilenos y su diferencia con los argentinos.

Sería interesante examinar otras geografías ficcionales recientes, ubicables en la estela de Copi, para ver hasta qué punto recurren a estrategias discursivas análogas y con qué fines parodian las fábulas nacionales de países vecinos. Pensamos, por ejemplo, en el complejo cuento « El gaucho insufrible » (recogido en El gaucho insufrible, 2002), del chileno Roberto Bolaño, una reescritura actualizada del género gauchesco que se presenta como un homenaje irónico a la literatura argentina, y como un replanteamiento del tópico civilización versus barbarie.

\section{BIBLIOGRAFÍA}

\section{Textos primarios :}

Aira, César, Los fantasmas, México, Era, 2002 (1990/1).

Contreras, Sandra, Las vueltas de César Aira, Rosario, Beatriz Viterbo Editora, 2002.

Copi, « El uruguayo ». En : Las viejas travestís y otras infamias, Barcelona, Anagrama, 1989, p. 77-139. Traducción española de Enrique Vila Matas. Edición original : L'Uruguayen, Paris, Christian Bourgois Editeur, 1972.

\section{Textos secundarios :}

Amícola, José, Camp y posvanguardia. Manifestaciones culturales de un siglo fenecido, Buenos Aires, Paidós, 2000.

Aira, César, Copi, Rosario, Beatriz Viterbo Editora, 2003 (1991/1). 
Dufays, Jean-Louis. « Estereotipo y teoría de la literatura : los fundamentos de un nuevo paradigma ». En : Revista Anthropos, n 196, 2002, p. 116-121.

Herralde, Jorge, «Canutos con Copi ». En : Revista Lateral, n 69, septiembre 2000, p. 38-39.

Kohan, Martín. 2002. « Partir sin partir del todo ». En línea en : http://

www.revistatodavia.com.ar/todavia25/1.kohannota.html (fecha de consulta : 15/06/2012)

Link, Daniel, « La carne dice ». En : Zigurat, n 4, noviembre 2003.

Logie, Ilse, «La transgresión de la identidad nacional en Copi ». En : Río de la Plata n²9/30, Relaciones culturales y literarias entre los países del Río de la Plata, Carmen Alemany Bay y Eva María Valero Juan (eds.), Universidad de Alicante, 2006, p. 419 -430.

Montaldo, Graciela, « La invención del artificio. La aventura de la historia ». En : Spiller, Roland (ed.), La novela argentina de los años 80, Frankfurt am Main, Vervuert, 1993, p. 257-269.

Montaldo, Graciela, « Vidas paralelas. La invasión de la literatura ». En : Michel Lafon, Cristina Breuil \& Margarita Remón-Raillard, César Aira, une révolution. Numéro hors série de Tigre, Grenoble, Université de Grenoble, 2005, p. 99-109.

Montoya Juárez, Jesús, « La televisión en la narrativa de César Aira o la mano del fantasma ». En : Monteagudo, $\mathrm{n}^{\circ}$ 15, 2010, p. 137-148.

Pron, Patricio, « Una carta imposible desde un país inexistente : Copi contra las convenciones narrativas en El uruguayo » (1972). En : Nina Grabe, Sabine Lang \& Klaus Meyer-Minneman (eds), La narración paradójica, Madrid/Frankfurt am Main, Iberoamericana/Vervuert, 2006, p. 209-220.

Pron, Patricio, "Aquí me río de las modas » : procedimientos transgresivos en la narrativa de Copi y su importancia para la constitución de una nueva poética en la literatura argentina. Tesis doctoral sin publicar, Universität Götingen 2007. En línea en : http://webdoc.sub.gwdg.de/diss/2007/pron/ pron.pdf. (fecha de consulta : 24/05/2012)

Rosenzvaig, Marcos, Copi, simulacro de espejos, Málaga, Universidad de Málaga, 2003.

Shumway, Nicolás, La invención de la Argentina, Buenos Aires, Emecé, 2002 (1991/1)

Silvestri, Graciela, « Por qué los porteños soñamos con Montevideo ». En : Revista Todavía, n 9, diciembre 2004. En línea en : http://www.revistatodavia.com.ar/todavia09/notas/silvestri/ txtsilvestri.html (fecha de consulta : 08/07/2012)

Vázquez, Laura, «La obra gráfica de Copi : vanguardia, política y exilio », Comunicación y medios, n • 19, 2009, p. 129-145. En línea en : http://www.comunicacionymedios.uchile.cl/index.php/RCM/ article/viewPDFInterstitial/11100/11403 (fecha de consulta : 12/07/2012)

Waldegaray, Marta, «El cruce al Uruguay : desplazamientos narrativos y espaciales en Los cautivos. El exilio de Echeverría, de Martín Kohan », Confluencia. Revista hispánica de cultura y literatura, vol. 22, $\mathrm{n}^{\circ} 1,2006$, p. 102-110.

Weiss, Jason, The Lights of Home. A Century of Latin American Writers in Paris, New York/London, Routledge, 2003.

\section{NOTAS}

1. Sobre este mismo tema, también se leerán con mucho provecho los trabajos de Martín Kohan (2002) y Marta Waldegaray (2006). 
2. Hay ejemplos recientes en el cine también, como XXY de Lucía Puenzo (2007), donde el desplazamiento al Uruguay permite mantener en suspenso una decisión.

3. Entendemos 'estereotipo' en el sentido que ha propuesto Dufays (1994) : sería un esquema de pensamiento preconstruido que comparten los individuos de una misma comunidad social o cultural y que contribuye a organizar sus representaciones colectivas. Para la sociocrítica, la noción de estereotipo opera como un elemento de mediación imprescindible ante el texto literario y el contexto social donde el texto ha surgido y frente al cual adquiere un sentido determinado. Los estereotipos forman parte de la competencia lectora y funcionan como hipótesis semánticas que luego son confirmadas o invalidadas.

4. Este apartado es una versión reelaborada y ampliada de una ponencia presentada en el congreso del CELCIRP en Alicante (véase Logie, 2006).

5. Mencionaremos el título de la versión original, pero citaremos la traducción española poniendo las páginas entre paréntesis. En la edición española, El uruguayo va incluido en el volumen de relatos Las viejas travestís y otras infamias. Es llamativo que L'Uruguayen haya sido traducido por el conocido escritor hispanocatalán Enrique Vila-Matas, lo que probablemente debe ser comprendido como una búsqueda deliberada de un efecto de extrañamiento, que se opone a la tendencia dominante en materia de traducción, la de la domesticación. La aclaración hecha en "Canutos con Copi» por el editor español de Copi, Jorge Herralde de Anagrama, confirma esta hipótesis : dice Herralde que Copi prefería que sus textos en francés fueran traducidos al español por un peninsular antes que por un latinoamericano.

6. El argumento es el siguiente : Rica y Usbek, un rico persa y su compañero, viajan a Europa. Se escriben mutuamente cuando están separados, y también escriben a sus amigos, padres y conocidos en Irán. A su vez, ellos reciben cartas. La colección de estas cartas forma el libro. Obedecen a la moda del orientalismo en boga en el siglo XVIII. La civilización persa es lo bastante respetable para resistir favorablemente la comparación con la civilización occidental, pero lo bastante criticable, a causa de la poligamia, de la reclusión de las esposas, etc., para justificar un reparto equivalente de los juicios de valor entre ambos términos de la comparación. El texto pone en escena la diferencia de civilizaciones, y la crisis que provoca el reconocimiento del otro y el asombro ante la diferencia. En la carta XXX, Rica describe la mirada que los parisinos le dirigen. Termina la carta con estas palabras : «Si alguien, por azar, decía a la gente que yo era persa, en seguida oía a mi alrededor un murmullo: ‘Ah, ah! ¿El señor es persa? ¡Qué cosa tan extraordinaria! ¿Cómo se puede ser persa?’". Se trata aquí de un guiño al lector, puesto que la pregunta que se sobreentiende es la siguiente : ‘Cómo se puede ser francés?'

7. Aunque 'ser uruguayo' no es tampoco nada muy definido, ningún compartimento estanco, y resulta rearticulado por Copi como un shifter que depende por completo de las coordenadas de la situación de enunciación.

\section{RESÚMENES}

En su nouvelle L'Uruguayen (1972), Copi construye un complejo juego de miradas que abarca los dos países del área rioplatense, Argentina y Uruguay, al tiempo que instaura una relación con Francia a través del procedimiento epistolar. De acuerdo con la poética de Copi, el Uruguay se presenta como exageración grotesca y burla del tradicional imaginario argentino acerca del país vecino, de índole utópica. La supuesta identidad uruguaya toma aquí la forma de una geografía 
ficcional, por lo que L'Uruguayen se muestra un precursor de textos seudoetnológicos más recientes como Los fantasmas (1990) de César Aira.

Dans sa nouvelle L'Uruguayen (1972), Copi construit un jeu complexe de regards croisés, qui d'un côté portent sur les deux pays de la région du Río de la Plata, l'Argentine et l'Uruguay, et de l'autre sur la France, impliquée par le procédé épistolaire. En consonance avec l'esthétique de Copi, l'Uruguay est présenté comme une exagération grotesque et une ridiculisation de l'imaginaire utopique développé par l'Argentine envers le pays voisin. La soi-disant identité de l'Uruguay prend ici donc la forme d'une géographie fictionnelle, raison pour laquelle L'Uruguayen peut être considéré comme un précurseur de textes pseudo-ethnologiques plus récents comme Los fantasmas (1990) de César Aira.

In his novelette L'Uruguayen (1972) Copi established a complex analysis from different perspectives, which looks at the two countries of the Rio de la Plata, Argentina and Uruguay on the one hand and France on the other, the text being conceived as a letter to a French correspondent. In keeping with Copi's poetics Uruguay is presented as a grotesque exaggeration, and the utopian image of the small neighboring country as it traditionally exists in Argentina is ridiculed. The so-called Uruguayan identity here takes the shape of a fictitious geography, so L'Uruguayen can be looked upon as a precursor of other, more recent pseudo-ethnological novels such as Los fantasmas (1990) by César Aira.

\section{ÍNDICE}

Mots-clés: géographie fictionnelle, Copi, Aira, Uruguay

Keywords: fictional geography

Palabras claves: geografía ficcional

\section{AUTOR}

\section{ILSE LOGIE}

Universiteit Gent 